\title{
Acute Liver Failure in an Antimitochondrial Antibody- Positive 63-Year-Old Man
}

\author{
Toru Wakamatsu Tatsuo Kanda Akinobu Tawada \\ Tatsuo Miyamura Masanori Takahashi Tetsuhiro Chiba \\ Makoto Arai Hitoshi Maruyama Keiichi Fujiwara \\ Fumio Imazeki Osamu Yokosuka \\ Department of Medicine and Clinical Oncology, Chiba University Graduate \\ School of Medicine, Chiba, Japan
}

\section{Key Words}

Primary biliary cirrhosis - Acute liver failure - Autoimmune hepatitis - Overlap syndrome

\begin{abstract}
Antimitochondrial antibody (AMA) is one of the representative features of primary biliary cirrhosis (PBC). PBC is a female-dominant disease usually presenting intrahepatic bile duct destruction, cholestasis and fibrosis with or without chronic nonsuppurative destructive cholangitis. We presented the case of a 63-year-old man with acute liver failure who had AMA, pronounced alanine aminotransferase elevation and high bilirubinemia. We administered corticosteroids and rescued this patient without liver transplantation. It is well known that some patients within the spectrum of autoimmune liver disease present with characteristics of both PBC and autoimmune hepatitis. Although corticosteroids may be associated with a significant worsening of adverse events in patients with $\mathrm{PBC}$, if acute liver failure in AMA-positive cases is progressive, the administration of corticosteroids has to be considered, as well as the preparation of urgent liver transplantation.
\end{abstract}

\section{Introduction}

Autoimmune hepatitis (AIH) patients usually present elevated serum aminotransferase levels (3-10-fold increase), marked hypergammaglobulinemia (typically IgG), positive titers of autoantibodies, histological findings of interface hepatitis and portal plasma cell infiltration [1], although atypical cases also exist [2-4]. Typical primary biliary cirrhosis (PBC) patients are females in the age range 
of 30-65 years, presenting with biochemical signs of cholestasis and the presence of antimitochondrial antibody (AMA), and they are asymptomatic or suffer from fatigue or pruritus [5-9]. Diagnosis can be made in patients who have elevated alkaline phosphatase (ALP) levels of at least 6 months duration, in combination with the presence of AMA ( $\geq 1: 40)$ [5]. Serum aminotransferase levels usually are only slightly elevated, whereas IgM concentration is typically increased [5].

Some patients within the spectrum of autoimmune liver disease present with characteristics of both PBC and AIH and are commonly classified as having an 'overlap syndrome' $[5,10]$. In AIH patients, AMA is occasionally seen at low titers, but an AMA anti-pyruvate dehydrogenase complex-E2 (AMA-M2) pattern, which is specific to PBC, is rarely detected [5]. Muratori et al. [11] reported that only $2 \%$ of type $1 \mathrm{AIH}$ patients were AMA-positive. Overlap cases are usually selected either on the basis of biochemical and serological findings or of histological features, although limitations due to biopsy size and sampling error should always be kept in mind in the assessment of a liver biopsy [5].

The acute and fulminant forms of AIH were recognized by the International Autoimmune Hepatitis Group in 1992, when it codified diagnostic criteria and waived the requirement for 6 months of disease activity to establish the diagnosis $[1,4]$, although it is still difficult to diagnose and treat the acute and fulminant forms of AIH $[2,4,12]$. We present a case of acute liver failure with overlap features of both PBC and $\mathrm{AIH}$ who was successfully treated with corticosteroids without liver transplantation.

\section{Case Report}

A 63-year-old Japanese man was referred to Chiba University Hospital at the end of April 2011 for the treatment of acute liver failure. Blood tests showed serum alanine aminotransferase (ALT) 2,415 IU/l, aspartate aminotransferase (AST) 3,253 IU/l, ALP $804 \mathrm{IU} / \mathrm{l}$, total bilirubin $12.7 \mathrm{mg} / \mathrm{dl}$, and prothrombin time international normalized ratio 1.65. Two weeks earlier, liver dysfunction had first been diagnosed at his regional clinic. At that time he had developed fatigue, pruritus and jaundice. Clinical data at admission to our hospital are shown in table 1. His medical history consisted of mild cerebral infarction 8 years before and surgery for inflammation of the right middle ear in his twenties. He had been taking medicines such as fenofibrate, allopurinol, diclofenac sodium, valsartan, nilvadipine and aspirin for hyperlipidemia, hyperuric acid, lumbar herniated disk and hypertension for more than 1 year. He occasionally drank alcohol and had no family history of liver diseases or autoimmune disorders. Physical examination on admission revealed jaundice but no consciousness disturbance. Computed tomography showed minimal ascites and mild hepatosplenomegaly with a

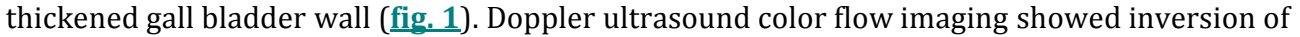
venous flow, suggesting portal hypertension, although endoscopic findings did not reveal any esophageal or gastric varices. There were no positivities of hepatitis viral markers (table 1). Possible reactivation of herpes simplex virus and drug-induced liver injury were not completely ruled out at that time. Because of the positivity for antinuclear antibody and AMA, especially AMA-M2, we considered him to have autoimmune liver disease such as AIH or overlap syndrome with characteristics of both PBC and AIH, and so the administration of corticosteroids was initiated [2]. He was first treated with 1,000-125 mg of methylprednisolone daily for 10 days, and then with 60-5 mg prednisolone daily for approximately 110 days. He also started taking $600 \mathrm{mg}$ of ursodeoxycholic acid daily for about 90 days. Total bilirubin continued to rise up to $31.2 \mathrm{mg} / \mathrm{dl}$, but then recovered. He was released from our hospital 120 days after admission. After his discharge, he was treated daily with $5 \mathrm{mg}$ of prednisolone and $600 \mathrm{mg}$ of ursodeoxycholic acid.

During his hospitalization, 70 days after the start of corticosteroid treatment, transjugular liver biopsy was performed ( $\underline{\text { fig. } 2}$ ). The liver biopsy specimen showed the architecture of the liver as being preserved, indicating no cirrhosis, but revealed submassive hepatic necrosis, findings compatible with 
overlap syndrome with characteristics of both PBC and AIH. The AIH score was 16 after completion of corticosteroid treatment, pointing to AIH compatibility [1].

One year later, he was well but complained of pruritus. His liver function tests were improved (ALT $11 \mathrm{IU} / \mathrm{ml}$, AST $22 \mathrm{IU} / \mathrm{ml}$, total bilirubin $0.6 \mathrm{mg} / \mathrm{dl}$, IgM $166 \mathrm{mg} / \mathrm{dl}$, and IgG 1,176 mg/dl), but his antinuclear antibody and AMA were still positive. Doppler ultrasound color flow imaging showed no inversion of venous flow and no ascites.

\section{Discussion}

We present a 63-year-old Japanese man with acute liver failure and positivity for AMA-M2 who was successfully treated with corticosteroids. Before admission he had no symptoms, and ALP was not examined. However, ALP levels were still elevated in mid-October 2011, AMA-M2 was still positive (8 IU/ml), and he had intractable pruritus, suggesting that $\mathrm{PBC}$ also existed. We diagnosed him as overlap syndrome having $\mathrm{AIH}$ and PBC features.

PBC-AIH overlap syndrome is a clinical entity characterized by the occurrence of both conditions at the same time in the same patient [13]. We and others previously reported the consecutive occurrence of AIH and PBC [9, 13]. It is very important for patients with acute liver failure such as the present case to be treated as soon as possible. We used corticosteroid therapy and made preparations for urgent liver transplantation $[14,15]$.

Corticosteroids may be associated with a significant worsening of osteoporosis in patients with PBC [5-7]. We previously reported that corticosteroids are effective for AIH with acute presentation [2] and that they are also effective for overlap syndrome having AIH and PBC features with acute transaminase elevation [10]. Ichai et al. [12] indicated that there is a point beyond which AIH cannot be salvaged by drug therapy, and this point can be defined only by assessing the immediate response to corticosteroid treatment [4]. This assessment can be made over a 2-week interval, which is sufficiently short to avoid the infectious complications associated with protracted immunosuppressive therapy and liver failure $[4,12]$. In our case, prothrombin time recovered relatively soon after the administration of corticosteroids. Corticosteroid therapy remains appropriate for severe, immediately life-threatening and fulminant AIH, although the treatment should be limited to 2 weeks or less [4].

We present a case of acute liver failure with overlap features with both PBC and AIH, who was successfully treated with corticosteroids without liver transplantation. In conclusion, it seems important to finely judge the corticosteroid use for atypical cases of autoimmune liver diseases with acute presentation over shorter periods. Of course, further studies are urgently needed.

\section{Acknowledgement}

The authors thank all medical staff at the Liver Unit of the Chiba University School of Medicine Hospital. 


\section{Disclosure Statement}

The authors have nothing to disclose.

Table 1. Laboratory data on admission to Chiba University Hospital

\begin{tabular}{llll}
\hline White blood cells & $10,300 / \mu \mathrm{l}$ & Gamma-glutamyl transpeptidase & $116 \mathrm{IU} / \mathrm{l}$ \\
Hemoglobin & $13.1 \mathrm{~g} / \mathrm{dl}$ & Total bilirubin & $18.0 \mathrm{mg} / \mathrm{dl}$ \\
Platelets & $38.2 \times 10^{4} / \mu \mathrm{l}$ & Direct bilirubin & $13.5 \mathrm{mg} / \mathrm{dl}$ \\
PT-INR & 1.33 & Immunoglobulin $\mathrm{M}$ & $286 \mathrm{mg} / \mathrm{dl}$ \\
$\mathrm{PT} \%$ & $49 \%$ & Immunoglobulin G & $1,928 \mathrm{mg} / \mathrm{dl}$ \\
Ammonia & $71 \mu \mathrm{g} / \mathrm{dl}$ & HBsAg & - \\
Total cholesterol & $88 \mathrm{mg} / \mathrm{dl}$ & Anti-HBs & - \\
Blood urea nitrogen & $12 \mathrm{mg} / \mathrm{dl}$ & Anti-HBc & - \\
Creatinine & $0.56 \mathrm{mg} / \mathrm{dl}$ & IgM-HBc & - \\
C-reactive protein & $2.9 \mathrm{mg} / \mathrm{dl}$ & HBV DNA & - \\
Alpha-fetoprotein & $9.0 \mathrm{ng} / \mathrm{ml}$ & IgM-HA & - \\
PIVKA-II & $37 \mathrm{mAU} / \mathrm{ml}$ & Anti-HCV & - \\
Total protein & $6.5 \mathrm{~g} / \mathrm{dl}$ & HCV RNA & - \\
Albumin & $3.3 \mathrm{~g} / \mathrm{dl}$ & Antinuclear antibody & $\times 640$ \\
Aspartate aminotransferase & $3,334 \mathrm{IU} / \mathrm{l}$ & AMA & $\times 40$ \\
Alanine aminotransferase & $2,602 \mathrm{IU} / \mathrm{l}$ & AMA-M2 & - \\
Lactate dehydrogenase & $568 \mathrm{IU} / \mathrm{l}$ & Anti-smooth muscle antibody & - \\
Alkaline phosphatase & $795 \mathrm{IU} / \mathrm{l}$ & & \\
\end{tabular}

$\mathrm{AMA}=$ Antimitochondrial antibody; Anti-HBc = hepatitis B core antibody, total; Anti-HBs = hepatitis B surface antibody; Anti-HCV = hepatitis $\mathrm{C}$ virus antibody; HBsAg = hepatitis B surface antigen; HBV DNA = hepatitis B virus DNA; IgM-HA = hepatitis A antibody immunoglobulin $\mathrm{M}$; IgM-HBc = hepatitis B core immunoglobulin M antibody; M2 = pyruvate dehydrogenase complex-E2 (PDC-E2); PIVKA-II = protein induced by vitamin K absence II; PT-INR = prothrombin time international normalized ratio. 


\begin{tabular}{r|l|l|l}
$\begin{array}{r}\text { Case Reports in } \\
\text { Gastroenterology }\end{array}$ & $\begin{array}{l}\text { Case Rep Gastroenterol 2012;6:394-399 } \\
\text { DOI: } 10.1159 / 000339915\end{array}$ & $\begin{array}{l}\text { Published online: } \\
\text { June 19, } 2012\end{array}$ & $\begin{array}{l}\text { C 2012 S. Karger AG, Basel } \\
\text { ISSN 1662-0631 } \\
\text { www.karger.com/crg }\end{array}$ \\
\hline
\end{tabular}
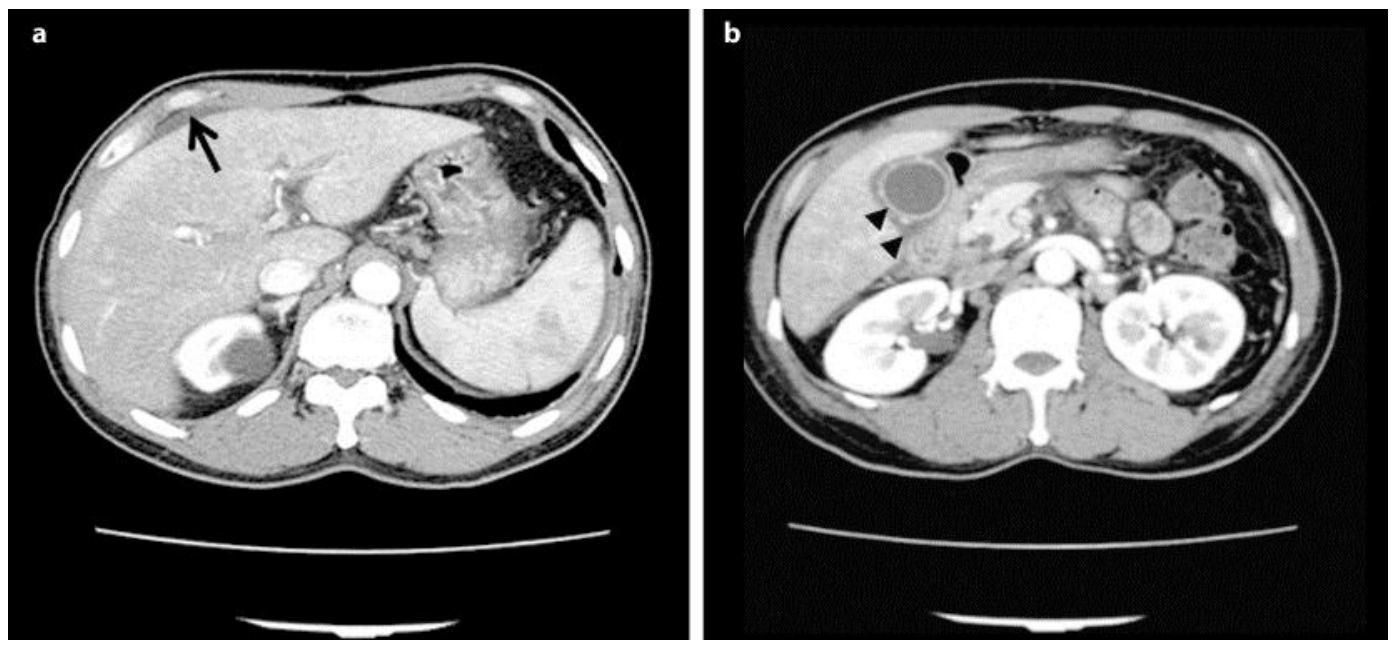

Fig. 1. Computed tomography on admission showed minimal ascites (arrow) and mild hepatosplenomegaly (a) with a thickened gall bladder wall (arrowheads) (b). These indicated severe liver injury.
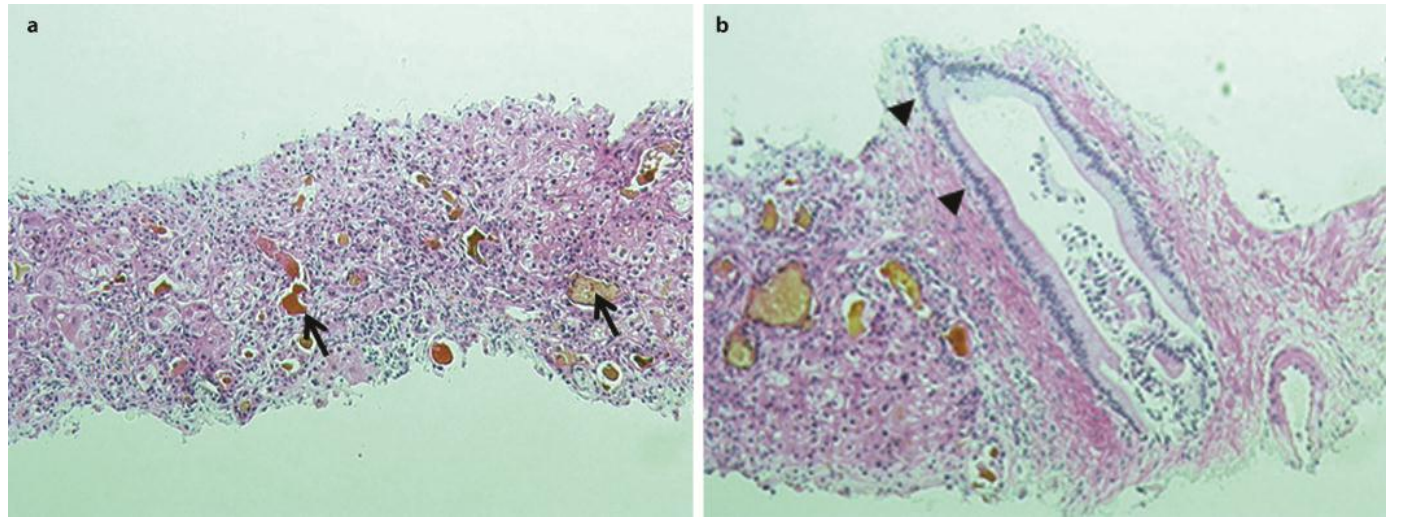

Fig. 2. Liver biopsy showed submassive hepatic necrosis and cholestasis (arrows) (hematoxylin and eosin; original magnification 40× (a) and florid bile duct regions (arrowheads) (hematoxylin and eosin; original magnification 200×) (b). The architecture of the liver was preserved, indicating no cirrhosis, but revealed submassive hepatic necrosis, findings compatible with overlap syndrome with characteristics of both PBC and AIH.

\section{References}

1 Johnson P, McFarlane IG: Meeting report: International Autoimmune Hepatitis Group. Hepatology 1993;18:998-1005.

-2 Kanda T, Yokosuka O, Hirasawa Y, Imazeki F, Nagao K, Suzuki Y, Saisho H: Acute-onset autoimmune hepatitis resembling acute hepatitis: a case report and review of reported cases. Hepatogastroenterology 2005;52:1233-1235.

-3 Manns MP, Czaja A, Gorham JD, Krawitt EL, Mieli-Vergani G, Vergani D, Vierling JM: Diagnosis and management of autoimmune hepatitis. Hepatology 2012;51:2193-2213.

4 Czaja AJ: Corticosteroids or not in severe acute or fulminant autoimmune hepatitis: therapeutic brinksmanship and the point beyond salvation. Liver Transpl 2007;13:953-955. 
5 Boerg KM, Chapman RW, Hirshfield GM, Lohse AW, Manns MP, Schrumpf E; International Autoimmune Hepatitis Group: Overlap syndromes: the International Autoimmune Hepatitis Group (IAIHG) position statement on a controversial issue. J Hepatol 2011;54:374-385.

-6 European Association for the Study of the Liver: EASL Clinical Practice Guidelines: management of cholestatic liver diseases. J Hepatol 2009;51:237-267.

7 Kanda T, Yokosuka O, Imazeki F, Saisho H: Bezafibrate treatment: a new medical approach for PBC patients? J Gastroenterol 2003;38:573-578.

-8 Kanda T, Yokosuka O, Imazeki F, Hirasawa Y, Ikeuchi T, Mikata R, Zhang KY, Kurihara T, Arai M, Fukai K, Saisho H, Mikami S, Azemoto R, Ito Y: Body mass index in Japanese patients with autoimmune liver disease: overweight patients with primary biliary cirrhosis tend to be asymptomatic. Hepatogastroenterology 2007;54:1758-1760.

9 Kanda T, Yokosuka 0, Kojima H, Imazeki F, Nagao K, Tatsuno I, Saito Y, Saisho H: Severe hypercholesterolemia associated with primary biliary cirrhosis in a 44-year-old Japanese woman. World J Gastroenterol 2004;10:2607-2608.

10 Kanda T, Yokosuka O, Hirasawa Y, Imazeki F, Nagao K, Saisho H: Occurrence of autoimmune hepatitis during the course of primary biliary cirrhosis: report of two cases. Dig Dis Sci 2006;51:45-46.

11 Muratori P, Granito A, Pappas G, Pendiano GM, Quarneti C, Cicola R, Menichella R, Ferri S, Cassani F, Bianchi FB, Lenzi M, Muratori L: The serological profile of the autoimmune hepatitis/primary biliary cirrhosis overlap syndrome. Am J Gastroenterol 2009;104:1420-1425.

-12 Ichai P, Duclos-Vallee JC, Guettier C, Hamida SB, Antonini T, Delvart V, Saliba F, Azoulay D, Castaing D, Samuel D: Usefulness of corticosteroids for the treatment of severe and fulminant forms of autoimmune hepatitis. Liver Transpl 2007;13:996-1003.

13 Poupon R, Chazouilleres 0, Corpechot C, Chretien Y: Development of autoimmune hepatitis in patients with typical primary biliary cirrhosis. Hepatology 2006;44:85-90.

14 Kanda T, Yokosuka O, Fujiwara K, Saisho H, Shiga H, Oda S, Okuda K, Sugawara Y, Makuuchi M, Hira sawa H: Fulminant hepatic failure associated with triazolam. Dig Dis Sci 2002;47:1111-1114.

15 Mitsuhashi N, Kimura F, Shimizu H, Imamaki M, Yoshidome H, Ohtsuka M, Kato A, Yoshitomi H, Nozawa S, Furukawa K, Takeuchi D, Takayashiki T, Suda K, Igarashi T, Miyazaki M: Usefulness of intraoperative fluorescence imaging to evaluate local anatomy in hepatobiliary surgery. J Hepatobiliary Pancreat Surg 2008;15:508-514

Toru Wakamatsu and Tatsuo Kanda contributed equally to this work. 